\title{
How to Solve New Contradiction: Perspective of Furniture Design
}

\author{
Huajie Shen \\ Material Science and Engineering School \\ Southwest Forestry University \\ Kunming, China \\ huajieshen@hotmail.com \\ Qizhao Lin \\ Material Science and Engineering School \\ Southwest Forestry University \\ Kunming, China \\ 1575177305@qq.com
}

\author{
Jian Qiu* \\ Material Science and Engineering School \\ Southwest Forestry University \\ Kunming, China \\ qiujianswfu@foxmail.com \\ Lei Qin \\ Material Science and Engineering School \\ Southwest Forestry University \\ Kunming, China \\ 307001926@qq.com
}

\begin{abstract}
The solution of New Contradictions is a research hotspot with the view of project management. In order to study the contribution of furniture design in solving New Contradictions, this article discusses the connotation and value of home, furniture and furniture design from six aspects: the basis of life, the creation of beauty, the realization of good life, the pursuit of a better life, the reduction of imbalance and the inadequate solution. That the basis of life is to have furniture at home, and to create "beauty" need for the design of furniture. The pursuit of a better life can promote ecological furniture design, narrowing the development imbalance is the performance of furniture to improve people's livelihood, and to solve the problem of inadequate development depending on the communication of furniture design. Looking at the all-round development of society, we can see that furniture design is not the only way to solve the "new contradiction" but it is an important thinking. Through the connotation of mining, viewing to arouse the people to pay attention to design, and the depth of furniture design is a discussion worthy of the sublimation direction.
\end{abstract}

Keywords-New Contradictions; furniture design; livelihood; furniture; ecological design

\section{INTRODUCTION}

The report of the 19th NPC pointed out [1]: as socialism with Chinese characteristics has entered a new era, the principal contradiction facing Chinese society has evolved. What Chinese now face is the contradiction between unbalanced and inadequate development and the people's evergrowing needs for a better life. This is the "New Contradiction" (NC) that researchers and mortal beings are concerned about. Recently, there have been more discussions on $\mathrm{NC}$, mainly from the aspects of concept, connotation, development thinking and solutions. In view of the major contradictions in the initial stage of socialism in our country, focusing on the functional reforms of government departments, Bai [2] believed that it is necessary to focus on the issue of equitable distribution of

Sponsors- Yunnan Science and Technology Department of applied basic research youth project "Bending performance evaluation several important timber species in Yunnan."(No.: 2017FD102); National Engineering Master's Degree in Postgraduate Education Online Curriculum Major Construction Project "Furniture Design and Manufacturing". infrastructure, educational resources, medical resources, scientific research institutes and industries. Xu [3] had interpreted the concept and connotation of $\mathrm{NC}$ in depth, although it did not propose a solution to the $\mathrm{NC}$ in the future development. Sheng[4] believed that exploring the inner relationship between the major social contradictions and the party's governing the state and administration should be the subject of a move toward a new journey of building a powerful nation in the socialist modern society. Liu [5] believed that resolving the $\mathrm{NC}$ must take the solution of the gap between the rich and the poor as the focal point and solving the unbalanced development issue through the implementation of the distributive justice in the field of production relations so as to satisfy people's need for a better life. Tang [6] believed that the solution needs to always adhere to the development of the most important task and vigorously enhance the quality and efficiency of development. Wei [7] believed that it is necessary to take Xi's socialism with Chinese characteristics as a guide in the new era, closely follow the connotation of NC. Liang [8] proceeded from the guide for action in realizing the great rejuvenation of the Chinese nation and discussed the solution to $\mathrm{NC}$

The discussion on the solution to NC has its own merits and demerits according to different researchers. Clearly, the similar focus on this field is People's Livelihood (PL), which is described that all of the development is from PL and share its feedback to PL. Wu [9] believed that the broad term of PL encompasses everything related to people's living, including directly related and indirectly related matters. While the narrow one mainly refers to the basic living and living conditions of the people as well as the people's basic development opportunities, basic development ability and the protection of basic rights and so on. As to both general one and narrow one, "home ownership" is the top important components of livelihood protection. To this field, furniture is undoubtedly the protagonist of "inside the house" and "outside the house". And the connotation and development of the furniture design can 
submit an answer sheet for NC. To answer it from the perspective of furniture design, we can focus on the key words of life, beauty, imbalance (IB), inadequate (IA) and furniture design (FD).

\section{THE BASIS OF LIFE: FURNITURE AT EVERY HOME}

\section{A. Life}

Broadly defined of life is referred to all kinds of human or animal activities. Narrowly one encompasses all kinds of human activities such as the basic necessities of life [10]. From the definitions, we could read that human differences and animal life are the commonalities of life, yet the specific groups differ from others is the personality of life [11]. No matter what style of life, or what time characteristics of life, life is an evaluation of the development of the Country. Besides, life is an important manifestation of social development media. To read life deeply, one could find that home is an important presence, but also a key link to link all the matters in society life [12]. According to Maslow's hierarchy of needs (shown in fig. 1), we can see that the existence or realization of various levels of demand can't be separated from the maintenance of life.

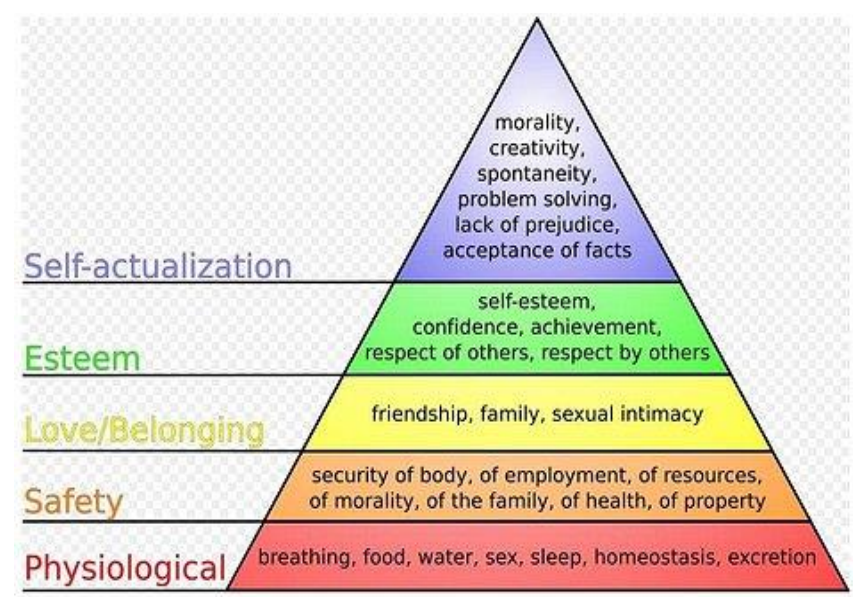

Fig. 1. Maslow demand hierarchy demo

\section{B. Furniture}

Furniture means one of the household devices or appliances [13]. In a broad sense, it refers to all kinds of utensils essential for human beings to maintain their normal lives, work productively and carry out social activities. In a narrow sense, it could be a class of appliances and equipment for living, working, or socializing for people to sit, lay, lie, or support for storing items. Furniture, but also can have daily necessities, industrial products, art carriers, space furnishings and other four categories of features (as shown in fig. 2). Furniture is an objective material existence, is one of the hallmarks of human civilization. When we humans and other animals had a basic difference, and began to have a dignified life, furniture had become to be the daily necessities of life. Modern furniture is mainly obtained from industrial production, which has typical characteristics of industrial products. Tian Zibing, a theory expert of Chinese arts and crafts, defined arts and crafts as a kind of fine art that makes material and spiritual products through the aesthetic processing of materials by means of production. In this definition, we can clearly understand that furniture is an emotional expression that is in line with the definition of an art carrier. Furniture has become a target that people must pay attention to because of its non-obtrusive character. The position and function of furniture in the interior has undergone fundamental changes. It mainly manifests in the transformation from props to scenes and the transformation from expressions to connotations. Thus we could interpret its connotation of space furnishings.

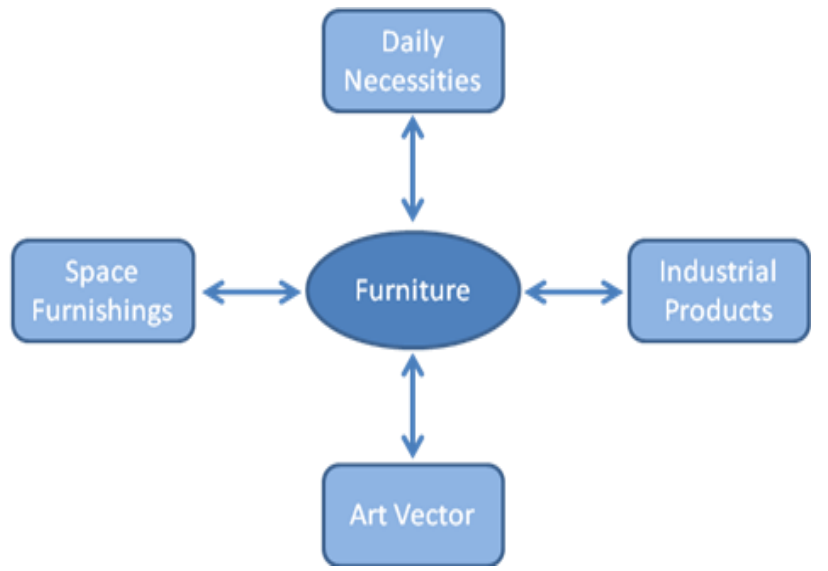

Fig. 2. Four ways to understand Furniture

\section{Relationship between Life and Furniture}

As well known in the world, life is the basis for the continuity of the state and social development, and home is the center of life. Inside of these, furniture is an important part of the family and an important foundation.

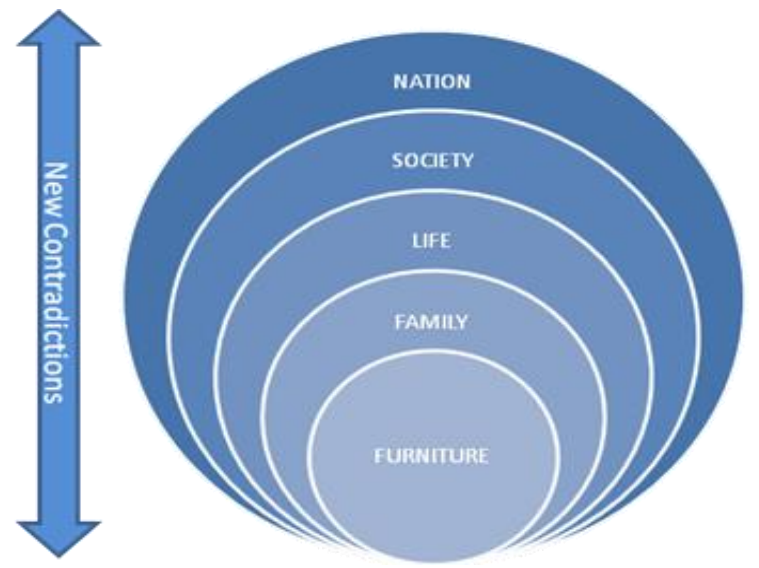

Fig. 3. Furniture's basement meaning

Must every family have furniture at home? The answer can be affirmative, because the furniture is expressed as household appliances or devices. However, the answer can also be negative, because the furniture in the eyes of the masses refers specifically to beds, tables, chairs and others as well. Progressively, we need to discuss whether every family has furniture needed at home. It is clearly to image that in many 
remote areas or poor areas such as Yunnan, it must be hard for one to find decent beds, tables, or chairs in a poor homes, though we can find mounds of rubbish or bricks that can be used for lying or sleeping, playing the roles of bed and seat.

There is furniture at each home, is the basis of our life. We have furniture at home, which is the starting point for our pursuit of a better life. There is furniture at home and this is what we need to solve in our precise anti-poverty efforts. What is more, it is one of the physical needs of the desire. To make every family has furniture at his home is our solution to grasp the overall situation when we focus on NC (shown in fig.3).

\section{POUR BEAUTY IN CREATING DECENT LIFE: FURNITURE ENJOYS DESIGN}

\section{A. Beauty}

The beauty is scheduled to discuss with different opinions. Beauty, as human evaluation of things, is one of our actions. Like any other human action, beauty is an activity of the brain from an individual's point of view. In order to define, analyze, and apply this activity, there have been developed theories that study beauty from the perspective of psychology and neuroscience, collectively referred to as Neuroesthetics [14]. It holds that, above all, beauty has a common law. If the common law about beauty does not exist, aesthetics, neuro-aesthetics, and the problem are totally empty. Second, the beauty exists on the basis of differences. Only by putting the same sensory signals into the brain (after dealing with different things, people may produce beautiful emotions, consciousness or memory, or else it is groundless.) For example, it must make no sense to distinguish the Mona Lisa from the wall, or to distinguish the characters from the background, and to distinguish the lines in the picture. Moreover, beauty is a kind of reflection of memory. We feel that thing A, in our memory there is a positive emotional connection about thing $\mathrm{B}$, and because $\mathrm{A}$ and $\mathrm{B}$ was established by the brain, A can stimulate emotions associated with $\mathrm{B}$, thus creating the feeling of beauty. Finally, the beauty is a kind of feedback. When the positive emotions are properly repeated repeatedly (the excess will be esthetic fatigue) Will enhance the memory of the association the formation of aesthetic memory. A group of common aesthetic memory is culture.

Aesthetics has entered its era of globalization. Zhang [15] thought that the origin of beauty came from the aesthetic judgment between the rational ability and the intellectual ability of man, but the essence of beauty was not the essence of beauty. The essence of beauty is the stipulation of four aspects of quality, quantity, relationship and modality that the aesthetic judgments unfold in the judgment activity. The Marxist esthetician defines beauty as the objectification of the essential force of man [16]. This is to regard aesthetic activities as social phenomena, combine beauty with the essential forces of human beings, and find the root of beauty from practice.

\section{B. Furniture Design}

Furniture Design (FD) [11] is based on their own understanding of society, human nature. Throughout the whole process, designers need to drive from the perspective of society, furniture producers and users, to develop and meet the furniture in the manufacture, to use process of appreciation plan of requirements and problems. From the concept that furniture is a daily necessity, we can understand one of the significance of FD is to guide and reflect the way of life. FD means a medium to life, reflecting the relationship between man and society, nature. FD is the design of lifestyles, meaning that any furniture design is inseparable from the real life. FD is a planning activity, is a creative activity, but also to meet people's needs, soul, the visual needs, even commercial purpose activities. From the describe of furniture is an industrial product, we must pay enough attention to the industrialization of furniture production, production design, production technology, production management, as well as production organization, product planning and marketing, product display and promotion, product use and maintenance, scrap processing, etc. must be included in the scope of furniture design.

Similarly, we have to discuss do every furniture has FD or not. The answer could be "yes", for the FD is always still there even if it is the exact example to make a stool based on the local material of wooden log. From this, we know that the concept of furniture design "spontaneous" existence. However, this design activity is an individual phenomenon. It only shows the basic needs of the seat manufacturer and the user for the seat, not the high-level practice. It is also difficult to satisfy the visual needs of the people in one go, and more difficult to integrate Sexual thinking play a positive role in furniture design activities.

\section{Beauty and FD}

The pursuit of beauty is a microcosm of the development of human civilization. It can be manifested in all aspects of basic necessities of life, but also can be reflected in the spiritual life.

Beauty is integrated. In terms of FD, the beauty of a beautiful life lies in the fact that the designers should not only have artistic inspiration, technical wisdom, but also have rich experience in life. The more furniture designers comprehend life, the more works of the better, the more classic, but also more easily with a comprehensive way of thinking to play furniture design in the new era of positive energy utility.

China's development track has entered a new historical position through long-term efforts from the poverty era to the food and clothing era, the well-to-do society, from building an overall well-to-do society to building a well-off society in an all-round way. A better life for the people needs an increasingly wide range of people, and places higher demands on material and cultural life as well. In this track of development, the furniture has undergone the transformation from "simple-furniture" to "decent-furniture" to "furnishing", and the FD has undergone a connotation development from "make useful" to "stereotype" to "flourishing". The realization of FD is undoubtedly a "beautiful" process of creating a decent life.

From the connotation of furniture, home and living, we can see that to create the "beauty" of a decent life, we must first realize the design of furniture, which being put the design of furniture designer's artistic inspiration and technical wisdom, as 
well as the emotion of stimulating users and critics Resonant design, rather than stay in the chewing ground to meet the design level of action.

\section{ACHIEVE A BETTER LIFE OF "GOOD" : FD IN ACTION}

GOOD, the positive energy of something needs to be exerted. Its existence can't be at the expense of other things, and it can affect the development of the related things toward the positive side. In product design, good design is creative, make the product available, make the product easy to understand, but out of fashion, throughout every detail, and caring about the environment.

Aesthetic point of view, you can interpret the beauty of furniture as beauty, functional beauty and artistic beauty three concepts. This concept helps us to understand "good". From the beginning of mankind will be the combination of function and aesthetic ideal, the beauty of furniture is a typical creature beauty. When a log becomes a seat, it can be convenient for people to "sit", which is its functional factor, even if it looks ugly. However, because of its ugly appearance, it has no characteristic of artistic beauty. Only when those meanings of form and color, the meaning of things themselves belong to the good feelings of people, that the artistic beauty risen. In life, people are accustomed to the popular beauty of the United States expressed as good-looking, easy to use, and full of funny. This expression deduces the hierarchical relationship between the three. In the product life cycle assessment system, one product often has its own "good looking" condition to open its life journey. It needs to be "easy to use" to realize its meaning in life. It must have a "fun" depth level connotation, that it can only deduce its classic design value, sublimate its added value of life. The three processes are not isolated from each other. "Funny" needs to meet the time and space conditions of "good looking" and "easy to use". Furniture is a necessary condition for life, the understanding of "good" and the realization of "good" undoubtedly incorporate the expressiveness of FD.

\section{THE PURSUIT OF A BETTER LIFE: FURNITURE ECO- DESIGN}

Starting from Maslow's demand level, it is easy to know that everyone begins to pursue a better life and is moving toward realizing self-worth. The pursuit of a better life, the ecological design of furniture can become a real and effective way. The main points of ecological design are: giving priority to the use of natural materials with sufficient sources, saving raw materials, simple material types, easy growth and circulation and harmless to humans and the environment, simple structure, easy disassembly and maintenance, durable products and long service life. Among them, sustainable development is a familiar vocabulary. Its main features are: to consider the future, consider the survival needs of future generations, and take into account the basic needs of people and the basic functions of products to solve the problems of recyclable energy and materials.

Furniture is reshaping and improving people's lives. No matter what the style, the design of furniture starts from the design of product function and shape, the appearance of traditional appearance and the design of aesthetics, to the cultural design, environmental design, atmosphere design and lifestyle design, focusing on the all-round experience and shaping. In the experience, both the subject and the object express their respective roles personally, fulfill their respective obligations, and put forward relevant opinions for the "good" FD or make corresponding expressions. At the heart of experiential design is the user center, not the product. Experiential FD is a manifestation of eco-design. The contrast of experiential FD reflects the historic context of NC that "the transformation of the main paradox from the long-accumulated material and cultural foundation". Therefore, it can be said: the ecological design of furniture is one of the ways to pursue a better life.

\section{REDUCE THE IMBALANCE: FD IMPROVES PEOPLE'S LIFE}

In globalization, the imbalance in development is a ubiquitous phenomenon and also the focus of attention of scholars from all walks of life. Similar to the development of the world, in recent years in China's development, imbalances in development are mainly regional and regional imbalances and imbalances between people and people.

Furniture is one of the highlights of social development. During the process of unbalanced development, furniture design plays a subtle influence. Recalling the development of modern industry, Chinese furniture has experienced more than 20 years from the importing country to the exporting country and has gone through more than 10 years as the first exporting country. Since becoming the largest export country in 2004, the Chinese furniture industry has been moving toward the goal of a powerful country of FD. This role change shows that the stage of the world furniture gradually toward China, deducing the Chinese furniture in narrowing the gap with the world furniture industry, the background of the times, that is, design is the core competitiveness of enterprises. In mainland China, the regional characteristics of furniture also confirm the fact that the development is not balanced. Representative "Pearl River Delta" and "Yangtze River Delta" furniture section is in every possible way to strengthen their "design" function, and to transfer the "manufacturing" function to central, and centralwestern regions, with a view to narrowing the imbalance.

Looking at the transformation process of the main contradictions, the FD has generally experienced the "furniture ticket" period in the planned economy, the prevalence of the slab furniture in the early reform period, the "Chinese modern furniture standard" period in the 1990s, and the rise in recent years of "Hundred Flowers bloom" period and other different periods. In this blooming hood, plate furniture, custom furniture, traditional furniture, new Chinese, minimalism, internationalism, national furniture, local furniture, designer brands, craftsmen manufacturing, smart home, etc. fight fighting; natural, people-oriented, system design thinking, functionalism design thinking, design originating from life, commercialized design ideas go hand in hand. This grand occasion of the long existence, happens to be the performance of furniture to improve people's livelihood. Because, on the one hand, the regional characteristics of furniture design reflect the reality of regional development and the differences between regions; on the other hand, the emergence of various trends of 
thought shows the coordinated existence of the common "person" and the individual "person".

\section{SOLVE INSUFFICIENCE: COMMUNICATION OF FD}

To solve the problem of insufficient development, we should promote the formation of a new pattern of opening up to the outside world, adhere to the principle of introducing and going out simultaneously, implement an open development strategy of initiative, openness and openness and mutual benefits, speed up the establishment of new advantages in international economic cooperation and competition, and constantly enhance our country's economic strength and overall national strength.

Technology is the primary productive force. Yet, design is not limited to creativity, but also communication and more productive. FD is the high-end part of the furniture industry is to open up the last mile of scientific and technological achievements into the scientific and technological advantages into an important new economic and social development an important way. FD as a key link in the transformation of scientific and technological achievements is to speed up the transfer of scientific and technological achievements. Besides, FD is setup to open up the channel of combining science and technology with economy and form an important engine of new productivity. To Furniture Fair, for example, FD is being changed from "worship" to Milan Furniture Fair in Italy and other international professional exhibitions, to "cultural confidence" gesture "please come" to blend with the Milan exhibition, to create Shanghai exhibition. This shift is widely acclaimed, and is addressing the inadequacies of furniture development. It is a shift that is a microcosm of the same change in all industries.

\section{CONCLUSION}

Indeed, FD is not a necessary solution to the NC, though it provides a design-thinking for the answer sheet. When analyzing the NC, we can solve the human instinct needs for "home ownership", "furniture from home" and "furniture design from furniture". From the perspective of good, we can solve the needs of people's behavior. The beauty of furniture is a reflection of people's thinking, showing their cultural, emotional and spiritual needs.

\section{ACKNOWLEDGMENT}

We would like to express our positive love to Yunnan Provincial Department of Education who provided a meaningful chance for us to learn in the name of visiting scholars in Center of Wood Anatomy Research (CWAR), a world-known research center belonged to United States Department of Agriculture.

\section{REFERENCES}

[1] Cao Ying. "How to reslove Nec contradiction." Xinhua Net, http://news.xinhuanet.com/politics/2017-10/24/c_129725444.htm. 201710-24 09:16:33.(In Chinese)

[2] Bai Mei. "Seize New Contradictions and Make Great Efforts to Solve the Problem of Insufficient Development Imbalance - New Contradictions in Learning from the Report of the 19th National Congress.” Price:Theory \& Practice, pp. 1-1. 2017. (In Chinese)

[3] Xu Xiaojie. "Comprehensively and Profoundly Understand and Understand New Contradictions in the New Era.", Journal of Fujian Provincal Committee Party School of CPC, pp. 7-9. 2017. (In Chinese)

[4] Sheng Mingke, Cai Zhenhua. "The Correlation Analysis of the Main Social Contradictions since the Founding of New China and the Theme of the Administration of the Party and the State." Journal of Xinjiang Normal University(Edition of Philosophy and Social Sciences), vol 4. pp 1-8. 2018.(published, In Chinese)

[5] Liu Tongfang. "The Necessary Logic behind the Main Social Conflicts in the New Era." Journal of South China Normal University(Social Science Edition), vol 6. pp. 1-5. 2017. (In Chinese)

[6] Tang Huangfeng. "The Transformation of Social Main Contradictions and the Strategic Choice of Our Country to Govern the Modernization in a New Era." Journal of Xinjiang Normal University(Edition of Philosophy and Social Sciences), vol 4. pp. 1-8. 2018.( In Chinese)

[7] Wei Xufang. "New Times, New Changes, New Connotations, New Requirements - How to Understand the Transformation of the Main Social Contradictions in Our Country.” Lingnan Journal, pp. 1-4. 2017. (In Chinese)

[8] Liang Zhongming. "On Xi Jin-ping's Socialist Theory with Chinese Characteristics in the New Era - A Guide to Actions for the Great Rejuvenation of the Chinese Nation." Studies on Party and Government, vol (6). pp. 1-6. 2017. (In Chinese)

[9] Wu Zhongmin. "Several rules should be followed to improve people's livelihood.” Social Policy Research, pp. 136-139. 2017. (In Chinese)

[10] Burrell, Gibson, and Gareth Morgan. Sociological paradigms and organisational analysis: Elements of the sociology of corporate life. Routledge, 2017:12

[11] Hua-Jie Shen, Jian Qiu, Han Liu. Some views on developing furniture industry in Yunnan under the background of Internet plus. 2nd Annual International Conference on Social Science and Contemporary Humanity Development. Wuhan, Hubei, China, July 15-17, 2016.

[12] Boulding KE. The image: Knowledge in life and society [M]. University of Michigan Press; 1956.

[13] Ward-Jackson PW. English furniture designs of the eighteenth century [M]. Victoria \& Albert Pubns; 1984.

[14] Tang Longfa. "What is the Beauty." Culture and Arts Publishing House , p. 34. 1986. (In Chinese)

[15] Zhang Zhengwen. "The Essence of Beauty: From the Origin of Beauty to Art - The Double Solution of Kant 's Essence to Beauty." Seeking Truth, vol (3). pp. 80-86. 2001. (In Chinese)

[16] Liang Shufa. "Question on "What is Marxism?" Journal of Renmin University of China, vol 4. pp. 69-74. 2000. (In Chinese) 